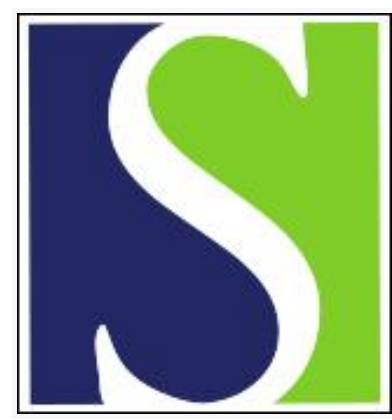

Scand J Work Environ Health 2004;30(3):234-240

https://doi.org/10.5271/sjweh.784

Issue date: Jun 2004

Incidence of ulnar nerve entrapment at the elbow in repetitive work

by Descatha A, Leclerc A, Chastang J-F, Roquelaure $Y$; the Study Group on Repetitive Work

Affiliation: Inserm U88-IFR 69, Hospital National de Saint-Maurice, 14 rue du Val d’Osne 94415 Saint-Maurice CEDEX, France. Annette.lecrerc@st-maurice.inserm.fr

Refers to the following texts of the Journal: 1995;21(6):450-459 2001;27(4):268-278

The following articles refer to this text: 2007;33(1):58-65; 2014;40(2):133-145; 2019;45(1):63-72

Key terms: elbow; incidence; repetitive work; ulnar nerve entrapment; work-related musculoskeletal disorder

This article in PubMed: www.ncbi.nlm.nih.gov/pubmed/15250652

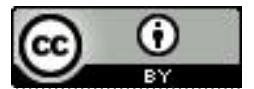




\title{
Incidence of ulnar nerve entrapment at the elbow in repetitive work
}

\author{
by Alexis Descatha, MD, ${ }^{1}$ Annette Leclerc, PhD, ${ }^{1}$ Jean-François Chastang, PhD, ${ }^{1}$ Yves Roquelaure, MD, ${ }^{2}$ \\ the Study Group on Repetitive Work ${ }^{3}$
}

\begin{abstract}
Descatha A, Leclerc A, Chastang J-F, Roquelaure Y, the Study Group on Repetitive Work. Incidence of ulnar nerve entrapment at the elbow in repetitive work. Scand J Work Environ Health 2004;30(3):234-240.

Objectives Despite the high frequency of work-related musculoskeletal disorders, the relation between work conditions and ulnar nerve entrapment at the elbow has not been the object of much research. In the present study, the predictive factors for such ulnar nerve entrapment were determined in a 3-year prospective survey of upper-limb work-related musculoskeletal disorders in repetitive work.

Methods In 1993-1994 and 3 years later, 598 workers whose jobs involved repetitive work underwent an examination by their occupational health physicians and completed a self-administered questionnaire. Predictive factors associated with the onset of ulnar nerve entrapment at the elbow were studied with bivariate and multivariate analyses.

Results The annual incidence was estimated at $0.8 \%$ per person-year, on the basis of 15 new cases during the 3year period. Holding a tool in position was the only predictive biomechanical factor [odds ratio (OR) 4.1, 95\% confidence interval (95\% CI) 1.4-12.0]. Obesity increased the risk of ulnar nerve entrapment at the elbow (OR $4.3,95 \%$ CI 1.2-16.2), as did the presence of medial epicondylitis, carpal tunnel syndrome, radial tunnel syndrome, and cervicobrachial neuralgia. The associations with "holding a tool in position" and obesity were unchanged when the presence of other diagnoses was taken into account.

Conclusions Despite the limitations of the study, the results suggest that the incidence of ulnar nerve entrapment at the elbow is associated with one biomechanical risk factor (holding a tool in position, repetitively), overweight, and other upper-limb work-related musculoskeletal disorders, especially medial epicondylitis and other nerve entrapment disorders (cervicobrachial neuralgia and carpal and radial tunnel syndromes).
\end{abstract}

Key terms work-related musculoskeletal disorder.

Upper-limb work-related musculoskeletal disorders are frequent in industrialized countries, especially tendinitis and nerve entrapment. Ulnar nerve entrapment at the elbow, also called cubital tunnel syndrome, is usually considered the second most common nerve entrapment disorder, after carpal tunnel syndrome (1).

While some authors (2) consider ulnar nerve entrapment at the elbow difficult to diagnose, even with EMG, definitions based on symptoms and signs are available for epidemiologic studies $(2,3)$. Nonetheless, as Bozentka (4) mentioned in his physiological study of this disorder, epidemiologic studies of occupational ulnar nerve entrapment at the elbow are rare (4). Most of the occupational studies are case reports in specific occupations or industrial sectors, such as driving (5), the shoe industry $(6,7)$, a bamboo toy factory (8), a surgical suture thread factory (9), occupations involving to hand-operated vibrating tools $(10,11)$, and professional musicians (12). Most of them do not include an assessment of exposure to biomechanical factors.

1 Institut National de la Santé et de la Recherche Médicale (National Institute for Health and Medical Research), U88IFR 69, Saint-Maurice, France.

2 Service de pathologie professionnelle, Centre Hospitalo-Universitaire (University Hospital), Angers, France.

3 Pierre Franchi and Fabrice Bourgeois, Agence Nationale pour l'Amélioration des Conditions de Travail; Paul Mereau, Institut National de Recherche et de Sécurité; Bernard Delemotte, Caisse Centrale de la Mutualité Sociale Agricole; Maryvonne Gournay, Marie-Claude Maillard, Dominique Quinton, Catherine Rondeau du Noyer, Annie Touranchet and Cécile Vallayer, Inspection Médicale du Travail, Christiane Teyssier-Cotte, Occupational Health Department, Besançon University Hospital.

Reprint requests to: Dr Annette Leclerc, Inserm U88-IFR 69, Hopital National de Saint-Maurice, 14 rue du Val d'Osne 94415 Saint-Maurice CEDEX, France. [E-mail: Annette.leclerc@st-maurice.inserm.fr] 
We based our study on data from a national survey that focused on work-related upper-limb disorders in general, with two medical examinations for each worker (1993-1994 and 1996-1997). The survey has been described in previous articles about carpal tunnel syndrome, wrist tendinitis, and epicondylitis (13-15). We analyzed ulnar nerve entrapment at the elbow with a longitudinal approach and looked at various predictive factors for its onset, including the presence of other workrelated musculoskeletal disorders.

\section{Participants and methods}

\section{Participants}

The sample used in this study has been described in previous papers (13-15). In 1993-1994, 1420 workers whose occupations required repetitive work and 337 who did not perform repetitive work completed a selfadministered questionnaire and were examined by the occupational health physicians in charge of the medical surveillance of the workers in their companies. These subjects were selected according to occupational criteria. Those with repetitive work belonged to one of the following activity sectors: assembly line (packaging excluded), clothing and shoe industry (packaging excluded), food industry (packaging excluded), packaging, and supermarket cashiering. With the exception of the supermarket cashiering, the groups were classified into groups representing 111 different "work situations", defined as similar work conditions at a common work location (most often the same workshop or the same assembly line). Three years later, 18 of the 39 physicians of the initial survey were able to repeat the examinations made earlier; they had examined 700 workers in repetitive work in 18 different firms. Of the 700 workers, $102(15 \%)$ were completely or partly lost to followup. Our present study is based on the findings from 598 workers in the longitudinal study. Most had the same or a similar job at baseline and 3 years later.

\section{Medical variables}

Guidelines prepared for the survey were used in the standardized clinical examination performed by the occupational health physicians at the beginning of the study and again 3 years later. A list of criteria for the diagnoses recorded in the medical questionnaire was prepared for this survey. The guidelines covered 33 diagnoses at the beginning of the study and 35 diagnoses at follow-up, the slight changes between the two lists being limited to shoulder tendinitis. One or two regional meetings with the occupational health physicians took place before the baseline study. Training for the standardized physical examination was included in these meetings. The guidelines were presented again in the regional meetings organized before the second survey.

The diagnosis of ulnar nerve entrapment at the elbow was based upon the following criteria: (i) sensory and motor symptoms in the ulnar nerve distribution, (ii) difficulties in moving the elbow, (iii) edema at the elbow, (iv) worsening of the symptoms by compression of the cubital tunnel, and (v) weakness and clumsiness of the hand.

We emphasized two criteria, sensory symptoms in the ulnar nerve distribution and worsening of the symptoms as a result of compression of the cubital tunnel. The diagnoses were classified into the following three categories: (i) proved diagnosis in the medical examination (all criteria met), (ii) proved diagnosis before the medical examination (eg, previous diagnosis by a specialist), and (iii) suspected diagnosis (not all the criteria met in the medical examination or diagnosis based on the description of symptoms no longer present at the time of the examination).

Our definition of a case of ulnar nerve entrapment included proved, suspected and prior diagnoses. "Prior diagnosis" in the second questionnaire included cases that had appeared during the 3-year interval. In the analysis of predictive factors of onset, we restricted the sample to workers not diagnosed with ulnar nerve entrapment at the elbow at baseline. We based the definitions exclusively on the results of the medical examination. The answers with respect to the arm diagram and the description of symptoms in the previous 6 months in the self-administered questionnaire were not taken into account in the analyses. However, these answers were checked for the "suspected" cases to verify that the symptoms were consistent with the diagnosis.

\section{Potential risk factors}

The list of potential risk factors comprised personal and occupational variables, postures, biomechanical constraints (self-assessed), and psychosocial work factors. It was based on the results of other studies on work-related upper-limb disorders, with special emphasis on risk factors for elbow disorders.

Personal and occupational variables. The following list represents the personal and occupational variables that were considered potential risk factors: (i) gender; (ii) age, in four categories (<30, 30-39, 40-49, >50 years); (iii) occupational variables, activity sector (of the 6 possible) and number of years on the job $(<1,1-9,>10$ years), (iv) smoking (nonsmoker, smoker, ex-smoker), (v) body mass index (BMI), normal $\left(\mathrm{BMI}<25 \mathrm{~kg} / \mathrm{m}^{2}\right)$, overweight $\left(\mathrm{BMI} \geq 25 \mathrm{~kg} / \mathrm{m}^{2}\right.$ and $<30 \mathrm{~kg} / \mathrm{m}^{2}$ ), obesity 
$\left(\mathrm{BMI} \geq 30 \mathrm{~kg} / \mathrm{m}^{2}\right)$, (vi) leisure-time activities, answer to the question "Do you often spend time participating in sports or playing music or on do-it-yourself house projects?" in two categories (yes or no), (vii) presence of psychosomatic or depressive problems, according to the answers to the following following questions: "Do you often have headaches?", "Do you often have sleep disorders?", "Are you often bothered by your heart beating hard?", "Do you have personal worries that get you down physically?", "Are you in low or very low spirits most of the time?", "Are you bothered by nervousness; do you often feel that nothing ever turns out the way you want it to?", and "Do you sometimes wonder if anything is worthwhile anymore?" The following three categories were defined for psychosomatic or deprsessive problems: "no problem", "some problems" (1 or 2 positive answers), "problems" (3 to 8 positive answers).

Postures and biomechanical constraints. The job tasks mentioned in the self-administered questionnaire included the following actions: "holding in position", "turning and screwing", "working with force" (any action performed with force), "using elbows for support", and "holding a tool in position" (using a tool that needs to be held in position). Two categories were considered, whether the action was performed repetitively or not. "Using a vibrating tool" was also considered as a twocategory variable, irrespective of frequency. As for other questions about work conditions, the responses with respect to postures and biomechanical constraints were checked with the physician.

Psychosocial work factors. Job control (scored from 0 to 8 ) was calculated as the sum of the following yes or no items: no choice for timing of breaks; unscheduled short breaks not possible; pace dictated by machine, colleagues, or other constraints; no control over the quantity of work; no control over the workpace; lack of variety. A low level of job control was defined as a score of $\geq 5$.

A low level of satisfaction was defined as a negative answer about either satisfaction with the workstation or general job satisfaction.

Other work-related musculoskeletal disorders. The disorders considered in the study were those affecting the elbow and also the following nerve compression disorders: lateral and medial epicondylitis, cervicobrachial neuralgia, median nerve syndrome at the elbow, radial tunnel syndrome at the elbow, carpal tunnel syndrome. Shoulder tendinitis was also considered, since workers affected by shoulder pain may modify their motions at work. Guyon's canal syndrome was considered separately, because it is closely associated with ulnar nerve entrapment at the elbow.

\section{Factors associated with loss to follow-up}

Loss to follow-up was significantly associated with age and activity sector. It was more frequent among both those younger than 30 years and those at least 50 years of age, and also among supermarket cashiers. There was no selection effect according to the medical conditions at baseline, except that those lost to follow-up more often complained of shoulder pain, with a substantial contribution from the relatively younger subgroup of supermarket cashiers.

The occupational health physicians were able to obtain information on the reason for loss to follow-up for 47 of the 102 lost to follow-up. The most frequent reasons were parental or maternity leave, resignation, and dismissal. Health reasons were reported less frequently.

\section{Statistical methods}

Statistical Analysis software (SAS) version 8.2 (SAS Institute, Cary, NC, USA) was used for the entire study.

Relations between ulnar nerve entrapment at the elbow in 1996-1997 and risk factors in 1993-1994 were studied for the 578 subjects free of ulnar nerve entrapment at the elbow at baseline, by bivariate associations (chi-square and Fisher tests). The variables associated with ulnar nerve entrapment at the elbow at a probability level of $\mathrm{P}<0.15$ were then studied with two separate logistic models, one with gender, age, and work-related musculoskeletal disorders present at baseline and the other with gender, age, and the risk factors other than work-related musculoskeletal disorders. In a last step, a final logistic model not only took into account gender and age, but also a limited number of the factors most strongly associated with ulnar nerve entrapment at the elbow according to the previous analyses.

It was planned to check the associations between ulnar nerve entrapment at the elbow and Guyon's canal syndrome. However, the diagnosis of Guyon's canal syndrome was absent from the medical questionnaires of all the incident cases of ulnar nerve entrapment at the elbow.

In addition, we looked at the frequency of two variables associated with the incidence of ulnar nerve entrapment at the elbow in the final multivariate model among the prevalent cases in the entire group of 1757 participants (1420 exposed to repetitive work, 337 unexposed) in 1993-1994. Our objective was to obtain additional information about the associations between these risk factors and ulnar nerve entrapment at the elbow, especially since the prevalent and incident cases were completely separate groups. 


\section{Results}

Among the 598 workers (420 women, 178 men) in the longitudinal study, 20 ( 15 women and 5 men) had a diagnosis of ulnar nerve entrapment at the elbow at baseline, of whom 7 were affected on the right side, 8 on the left, and 5 bilaterally. Three years later, 18 of the 20 cases had recovered. The five workers with bilateral entrapment had recovered. In 1996-1997, there were 17 prevalent cases, 10 affected on the right side, 3 on the left side, and 4 on both sides. Of the 17 cases, 15 were incident cases, making an incidence rate of about $0.8 \%$ per person-year. Seven of them were classified as "proved in the medical examination" and seven as "suspected". The last case, classified as "proved diagnosis before the medical examination", had undergone surgery for ulnar nerve entrapment at the elbow 2 years earlier. Among the seven suspected cases, three had paresthesia exclusively in the fourth and fifth digits according to the self-administered questionnaire. Three had paresthesia also in other digits. For them the occupational physicians had given a diagnosis of carpal tunnel syndrome in addition to ulnar nerve entrapment at the elbow. One had pain in the elbow.

Two physicians had three incident cases, three had two cases, and three had one case.

Among the 15 incident cases, 10 were employed on an assembly line (4 for household electrical appliances, 3 for car brakes, 2 for electronic appliances and 1 for ski accessories). Three were in the shoe industry, two in packaging in the food industry (one packaging bread and the other sticking labels in the meat industry).

The factors associated with incidence were studied in the group of 578 workers who did not have ulnar nerve entrapment at the elbow at baseline. Among the potential personal and occupational predictive factors, the bivariate analyses (table 1) indicated that gender, presence of psychosomatic or depressive problems, body mass index, "using elbows for support", and "holding a tool in position" were associated with incidence. These variables, together with age and activity sector, were included in a logistic model. The model (not given) indicated that obesity and "holding a tool in position" were significantly associated with the incidence of ulnar nerve entrapment at the elbow. "Supporting with the elbow" remained in the model, with an OR of 3.73 and a $95 \%$ confidence interval of 0.71-19.64.

The associations between the presence of other work-related musculoskeletal disorders in 1993-1994 and the incidence of ulnar nerve entrapment at the elbow were studied separately. Medial epicondylitis, cervicobrachial neuralgia, and radial and carpal tunnel syndromes were associated with the incidence of ulnar nerve entrapment at the elbow (table 2). When these four disorders were taken into account simultaneously in a
Table 1. Potential risk factors for the 3-year incidence of ulnar nerve entrapment at the elbow. ( $\mathrm{OR}=$ odds ratio, $95 \% \mathrm{Cl}=95 \%$ confidence interval)

\begin{tabular}{|c|c|c|c|c|c|}
\hline Potential risk factor & $\begin{array}{l}\text { Partici- } \\
\text { pants }{ }^{a} \\
\text { (N) }\end{array}$ & $\begin{array}{l}\text { Inci- } \\
\text { dent } \\
\text { cases }^{b} \\
\text { (N) }\end{array}$ & $\begin{array}{c}\text { Cumula- } \\
\text { tive inci- } \\
\text { dence c } \\
(\%)\end{array}$ & $\mathrm{OR}$ & $95 \% \mathrm{Cl}$ \\
\hline \multicolumn{6}{|l|}{ Gender } \\
\hline Men & 173 & 1 & 0.6 & 1 & $\cdot$ \\
\hline Women & 405 & 14 & 3.5 & 6.16 & $0.80-47.21$ \\
\hline \multicolumn{6}{|l|}{ Age } \\
\hline$<30$ years & 115 & 2 & 1.7 & 1 & $\cdot$ \\
\hline 30-39 years & 219 & 5 & 2.3 & 1.32 & $0.25-6.91$ \\
\hline $40-50$ years & 192 & 5 & 2.6 & 1.51 & $0.29-7.92$ \\
\hline$>50$ years & 52 & 3 & 5.8 & 3.46 & $0.56-21.36$ \\
\hline \multicolumn{6}{|l|}{ Activity sector } \\
\hline Assembly line & 236 & 10 & 4.2 & . & $2.6-5.8 \% d$ \\
\hline Supermarket cashiering & 42 & 0 & 0.0 & & \\
\hline Clothing and shoes industr & ry 61 & 3 & 4.9 & $\cdot$ & $3.1-6.7 \%{ }^{d}$ \\
\hline Food industry & 140 & 0 & 0.0 & & \\
\hline Packaging & 99 & 2 & 2.2 & $\cdot$ & $1.0-3.4 \%{ }^{d}$ \\
\hline \multicolumn{6}{|l|}{ Number of years on the job } \\
\hline$<1$ years & 203 & 5 & 2.5 & 1 & $\cdot$ \\
\hline $1-10$ years & 307 & 7 & 2.3 & 0.92 & $0.29-2.96$ \\
\hline$>10$ years & 68 & 3 & 4.4 & 1.83 & $0.43-7.86$ \\
\hline \multicolumn{6}{|l|}{ Smoking } \\
\hline Nonsmoker & 202 & 5 & 2.5 & 1 & $\cdot$ \\
\hline Smoker & 325 & 9 & 2.8 & 1.12 & $0.37-3.40$ \\
\hline Ex-smoker & 51 & 1 & 2.0 & 0.79 & $0.09-6.90$ \\
\hline \multicolumn{6}{|l|}{ Body mass index } \\
\hline Normal & 397 & 8 & 2.0 & 1 & $\cdot$ \\
\hline Overweight & 138 & 3 & 2.2 & 1.08 & $0.28-4.13$ \\
\hline Obesity & 43 & 4 & 9.3 & 4.99 & $1.44-17.32$ \\
\hline \multicolumn{6}{|l|}{ Leisure-time activities } \\
\hline No & 281 & 6 & 2.1 & 1 & $\cdot$ \\
\hline Yes & 297 & 9 & 3.0 & 1.43 & $0.50-4.08$ \\
\hline \multicolumn{6}{|c|}{ Presence of psychosomatic or depressive problems } \\
\hline Score 0 & 323 & 5 & 1.6 & 1 & $\cdot$ \\
\hline Score 1 or 2 & 174 & 8 & 4.6 & 3.07 & $0.99-9.52$ \\
\hline Score 3 to 8 & 81 & 2 & 2.5 & 1.61 & $0.31-8.45$ \\
\hline \multicolumn{6}{|l|}{ Holding in position } \\
\hline No & 206 & 5 & 2.4 & 1 & $\cdot$ \\
\hline Yes & 372 & 10 & 2.7 & 1.11 & $0.37-3.29$ \\
\hline \multicolumn{6}{|l|}{ Turning and screwing } \\
\hline No & 416 & 11 & 2.6 & 1 & $\cdot$ \\
\hline Yes & 162 & 4 & 2.5 & 0.93 & $0.29-2.97$ \\
\hline \multicolumn{6}{|l|}{ Working with force } \\
\hline No & 248 & 6 & 2.4 & 1 & $\cdot$ \\
\hline Yes & 330 & 9 & 2.7 & 1.13 & $0.40-3.22$ \\
\hline \multicolumn{6}{|l|}{ Using elbows for support } \\
\hline No & 553 & 13 & 2.4 & 1 & $\cdot$ \\
\hline Yes & 25 & 2 & 8.0 & 3.61 & $0.77-16.95$ \\
\hline \multicolumn{6}{|l|}{ Holding a tool in position } \\
\hline No & 401 & 6 & 1.5 & 1 & $\cdot$ \\
\hline Yes & 177 & 9 & 5.1 & 3.53 & $1.24-10.06$ \\
\hline \multicolumn{6}{|l|}{ Using a vibrating tool } \\
\hline No & 475 & 11 & 2.3 & 1 & $\cdot$ \\
\hline Yes & 103 & 4 & 3.9 & 1.70 & $0.53-5.46$ \\
\hline \multicolumn{6}{|l|}{ Job control } \\
\hline Low level & 369 & 10 & 2.7 & 1 & . \\
\hline High level & 209 & 5 & 2.4 & 0.88 & $0.30-2.61$ \\
\hline \multicolumn{6}{|l|}{ Satisfaction at work } \\
\hline High level & 530 & 13 & 2.5 & 1 & $\cdot$ \\
\hline Low level & 48 & 2 & 4.2 & 1.73 & $0.38-7.90$ \\
\hline
\end{tabular}

a Total number of participants 578 .

Total number of incident cases 15

c Total cumulative incidence 2.6.

d For activity sector, $95 \% \mathrm{Cl}$ of incidence. 
Table 2. Presence of work-related musculoskeletal disorders at baseline and the incidence of ulnar nerve entrapment at the elbow. (NS = not significant)

\begin{tabular}{lcccl}
\hline Disorder & $\begin{array}{c}\text { Partic- } \\
\text { ipants } \\
(\mathrm{N})^{\mathrm{a}}\end{array}$ & Cases $^{\mathrm{b}}$ & $\begin{array}{c}\text { Cumulative } \\
\text { incidence } \\
(\%)^{\mathrm{c}}\end{array}$ & $\begin{array}{c}\text { P-value } \\
\text { (Fisher } \\
\text { exact test) }\end{array}$ \\
\hline Shoulder tendinitis & & & \\
No & 369 & 8 & 2.2 & NS \\
Yes & 209 & 7 & 3.4 & \\
Lateral epicondylitis & & & \\
No & 509 & 12 & 2.4 & NS \\
Yes & 69 & 3 & 4.4 & \\
Medial epicondylitis & & & \\
No & 550 & 11 & 2.0 & $\mathrm{P}<0.01$ \\
Yes & 28 & 4 & 14.3 & \\
Cervicobrachial neuralgia & & & \\
No & 539 & 12 & 2.2 & $\mathrm{P}=0.07$ \\
Yes & 39 & 3 & 7.7 & \\
Median tunnel syndrome at elbow & & \\
No & 567 & 14 & 2.5 & NS \\
Yes & 11 & 1 & 9.1 & \\
Radial tunnel syndrome at elbow & & \\
No & 574 & 14 & 2.4 & $\mathrm{P}=0.10$ \\
Yes & 4 & 1 & 25.0 & \\
Carpal tunnel syndrome & & & \\
No & 457 & 8 & 1.8 & $\mathrm{P}<0.05$ \\
Yes & 121 & 7 & 5.8 & \\
\hline
\end{tabular}

a Total number of participants 578 .

b Total number of cases of ulnar entrapment at the elbow 15.

c Total cumulative incidence 2.6.

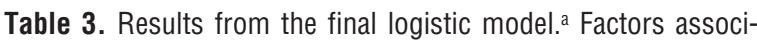
ated with the 3-year incidence of ulnar nerve entrapment at the elbow. ${ }^{b}(\mathrm{OR}=$ odds ratio, $95 \% \mathrm{Cl}=95 \%$ confidence interval)

\begin{tabular}{|c|c|c|c|}
\hline Factor & $\mathrm{OR}$ & $95 \% \mathrm{Cl}$ & P-value \\
\hline \multicolumn{4}{|l|}{ Gender } \\
\hline Men & 1 & . & 0.14 \\
\hline Women & 4.93 & $0.59-41.27$ & $\cdot$ \\
\hline \multicolumn{4}{|l|}{ Age } \\
\hline$<30$ years & 1 & . & 0.82 \\
\hline $30-39$ years & 0.68 & $0.12-3.91$ & . \\
\hline $40-50$ years & 0.68 & $0.2-3.96$ & . \\
\hline$>50$ years & 1.30 & $0.19-0.02$ & . \\
\hline \multicolumn{4}{|c|}{ Body mass index } \\
\hline Normal & 1 & . & 0.08 \\
\hline Overweight & 1.02 & $0.25-4.12$ & . \\
\hline Obesity & 4.30 & $1.13-16.39$ & . \\
\hline \multicolumn{4}{|c|}{ Holding a tool in position } \\
\hline No & 1 & $\cdot$ & 0.01 \\
\hline Yes & 4.11 & $1.38-12.23$ & $\cdot$ \\
\hline \multicolumn{4}{|c|}{ Presence of another upper-limb work-related musculoskeletal disord } \\
\hline No & 1 & . & 0.001 \\
\hline Yes & 5.09 & $1.54-16.82$ & . \\
\hline
\end{tabular}

logistic model, all of them remained significantly associated with the incidence of ulnar nerve entrapment at the elbow. Therefore, the variable taking into account the presence of other work-related musculoskeletal disorders in the final model was the presence of at least one of these four disorders.

In addition to gender and age, the final logistic model included the three variables most strongly associated with ulnar nerve entrapment at the elbow (ie, body mass index, holding a tool in position, and presence of another work-related musculoskeletal disorder). These three risk factors remained associated with the incidence of ulnar nerve entrapment at the elbow, as indicated in table 3 .

We checked whether the frequency of "holding a tool in position", overweight, and presence of another work-related musculoskeletal disorder was high at baseline among the incident cases if the definition of incidence was restricted to "proved diagnosis in the medical examination". The frequencies were $57 \%$ for "holding a tool in position" (31\% of the whole sample), $29 \%$ for obesity ( $7 \%$ of the whole sample), and $71 \%$ for presence of another work-related musculoskeletal disorder (30\% of the whole sample) in the list.

Holding a tool in position and body mass index were also examined to see whether either of them was associated with the prevalence of ulnar nerve entrapment at the elbow in the entire sample in 1993-1994. The prevalence was $2.1 \%$ (37 cases among 1757 persons). The association with body mass index was of borderline significance $(\mathrm{P}=0.051)$, the prevalence being $9.30 \%$ for obese persons, $2.11 \%$ for those simply overweight, and $2.42 \%$ for those with normal weight. The prevalence was significantly higher $(3.85 \%$ versus $1.47 \%, \mathrm{P}=0.002)$ for those who had to hold a tool in position.

\section{Discussion}

Our study suggested that ulnar nerve entrapment at the elbow is associated with occupational risk factors (more precisely with "holding a tool in position"), with personal factors (obesity), and with the presence of other upper-limb disorders, especially medial epicondylitis and other nerve entrapments. The study had some limitations, however, that must be taken into account. Although the criteria for ulnar nerve entrapment at the elbow resembled those recommended in recent papers (3, $4)$, there was no confirmatory nerve conduction study performed for the 15 incident cases, and the criteria for "suspected" diagnosis were not explicit. The postures and biomechanical constraints had been self-assessed. Another limitation was the small number of cases.

The study was based entirely on clinical diagnosis. The pressure provocative test, which was one of the criteria 
needed for proved cases, has a specificity of 0.98 , according to a study of the sensitivity and specificity of provocative tests for ulnar nerve entrapment at the elbow (16). "Suspected" diagnoses of ulnar nerve entrapment at the elbow were based on the evaluation of an occupational health physician, and no minimum number of criteria had been given in the guidelines. However, for the suspected cases, the symptoms described in the self-administered questionnaire were consistent with the diagnosis given by the physician.

In this study postures and biomechanical constraints were self-assessed, but the answers were checked with the physician. In addition, the frequency of each constraint was calculated for each "work situation", and the results were discussed with the occupational health physicians in charge of health surveillance in the firms, in order to be sure that, for all work situations, the description of the work conditions, based on the questionnaires, was consistent with the "expert opinion" of the occupational health physician.

Many occupational health physicians were involved in the study, and this participation may have induced observer bias, although there was specific training for the study, which was intended to improve the comparability of the medical examinations. The 598 workers in this longitudinal study were not selected according to health criteria, and the selection for health reasons between the first and second questionnaires was minimal (15). Most participants, even those who suffered from upper-limb disorders in 1993-1994, were exposed to similar constraints at baseline and at follow-up. Nevertheless, the occupational health physicians at firms with a high level of upper-limb disorders volunteered more often for the longitudinal study.

Ulnar nerve entrapment at the elbow has been described by Hagberg et al as the second most common form of occupational upper-limb nerve entrapment, after carpal tunnel syndrome (1), and our study confirmed this ranking. This disorder is nonetheless infrequent, which partly explains the lack of epidemiologic data on occupational factors. For a population exposed to repetitive and forceful movements, Pellieux et al estimated its annual incidence rate at $2.6 \%$, based on claims for occupational diseases (9). Higher prevalence levels have been observed in some studies or populations: $40 \%$ in a group of 69 musicians (12) and $42.5 \%$ (subclinical ulnar nerve entrapment at the elbow, ie, increased motor conduction of the ulnar nerve at the elbow) for 167 workers who used hand-operated vibrating tools (10).

The only biomechanical factor in the final logistic model was "holding a tool in position". The workers who responded that they were required to hold a tool in position, repetitively, used various tools, such as pliers, cutting pliers, shoe rivets, spatulas, and screwdrivers. "Repetitively" implied intensive use, since the cycle time was less than 30 seconds for half of the workers, $\geq 1$ minute for only $28 \%$ of them (14). The association with "holding a tool in position" has not been mentioned in other studies on ulnar nerve entrapment at the elbow, but it was found in those that focused more on the role of vibration, including vibration from sewing machines (in the shoe industry), than on the repetitive use of tools. In our study "exposure to vibrating tools" was restricted to hand-held tools, and "holding a tool in position" seemed to be more important for ulnar nerve entrapment at the elbow than exposure to vibration issued from a sewing machine (which is met by almost all the workers in the clothing and shoe industries). The three incident cases in the shoe industry had to hold a tool in position, repeatedly, in addition to using a sewing machine. In bivariate analyses, ulnar nerve entrapment at the elbow was also associated with "using elbows for support". Many authors have reported that elbow flexion and extension are involved in the occurrence of ulnar nerve entrapment at the elbow $(4,17-21)$. The ulnar nerve enters the cubital tunnel by passing posteriorly to the medial epicondyle. The boundaries of the fibro-osseous cubital tunnel involved in "cubital tunnel entrapment" in the elbow (alternative name for ulnar nerve entrapment at the elbow) are the olecranon and the ulnar collateral ligament laterally, the medial epicondyle with the ulnar nerve sulcus anteriorly, and the cubital tunnel retinaculum (also called Osborn ligament), and the bridging aponeurosis of the two heads of the flexor ulnar carpi muscle (one of the medial epicondyle muscles) medially (21-25). Anatomic studies explain the effects of repetitive strain on the ulnar nerve at the elbow, and this explanation furthers the understanding of the physiopathology of the disorder $(25,26)$. The association observed between obesity and ulnar nerve entrapment at the elbow can be explained by mechanisms similar to those involved in carpal tunnel syndrome, dealing with the increase of fat and edema in the cubital tunnel.

The association between ulnar nerve entrapment at the elbow and ulnar nerve entrapment at the wrist (Guyon's syndrome) could not be studied because the ulnar nerve is involved in both disorders. The association with other work-related musculoskeletal disorders was expected, especially medial epicondylitis and carpal tunnel syndrome. The association with other nerve entrapment disorders, such as carpal tunnel syndrome or thoracic outlet syndrome (grouped with cervicobrachial neuralgia in the 1993-1994 examination in our study) was also expected $(10,17)$. The association between ulnar nerve entrapment at the elbow and cervicobrachial neuralgia is difficult to assess since they can easily be mistaken for each other in that the symptoms are partly the same.

Our results suggest that workers with one work-related musculoskeletal disorder have an increased risk for 
others, such as ulnar nerve entrapment at the elbow, especially if occupational risk factors are also present. They require special attention.

\section{Acknowledgments}

The study was conducted with financial support from the National Institute for Health and Medical Research (INSERM).

We thank the 18 occupational health physicians who took part in the longitudinal study.

\section{References}

1. Hagberg M, Silverstein BA, Wells R, Smith MJ, Herbert R, Hendrick HW, et al. Work related musculoskeletal disorders (WMSDs): a reference book for prevention. 2nd edition. Bristol (UK): Taylor and Francis; 1997.

2. Sluiter JK, Rest KM, Frings-Dresen MHW. Criteria document for evaluating the work-relatedness of upper-extremity musculoskeletal disorders. Scand J Work Environ Health 2001;27 Suppl 1:1-102.

3. Piligian G, Herbert R, Hearns M, Dropkin J, Landsbergis P, Cherniack M. Evaluation and management of chronic workrelated musculoskeletal disorders of the distal upper extremity. Am J Ind Med 2000;37(1):75-93

4. Bozentka DJ. Cubital tunnel syndrome pathophysiology. Clin Orthop 1998;351:90-4.

5. Abdel-Salam A, Eyres KS, Cleary J. Drivers' elbow: a cause of ulnar neuropathy. J Hand Surg [Br ] 1991;16(4):436-7.

6. Agnesi R, Dal Vecchio L, Todros A, Sparta S, Valentini F. Neuropatia del nervo ulnare a livello del gomito in addette all'uso di macchine per cucire a colonna: casistica e followup [Ulnar neuropathy at the elbow in workers using column sewing machines: case reports and follow-up]. Med Lav 1993;84(2):147-61.

7. Perbellini L, De Grandis D, Marchiori L, Olivato D, Bertolasi L. Neuropatie periferiche da posture incongrue in lavoratori calzaturieri [Peripheral neuropathy caused by incongruous posture in shoe manufacture workers]. Med Lav 1989; 80(2):140-7.

8. Bonfiglioli R, Lodi V, Tabanelli S, Violante FS. Intrappolamento del nervo ulnare al gomito da movimenti ripetitivi: descrizione di un caso clinico [Ulnar nerve entrapment and repetitive movements: description of a case]. Med Lav 1996;87(2):147-51

9. Pellieux S, Fouquet B, Lasfargues G. Syndrome du nerf ulnaire au coude et maladie professionnelle: analyse des paramètres socioprofessionnels et physiques [Ulnar nerve tunnel syndrome at the elbow and occupational disease: description of socio-professional and physical parameters]. Ann Readaptation Med Phys 2001;44(4):213-20.

10. Kakosy T. Tunnel syndromes of the upper extremities in workers using hand-operated vibrating tools. Med Lav 1994;85(6):474-80.

11. Todaro A, Tomasini M, Di Carlo D, Consonni D, Mariani E. Neuropatia da strumenti vibranti: studio clinico-diagnostico in un gruppo di soggetti sintomatici [Neuropathies caused by vibrating devices: clinico-diagnosis study of a group of symptomatic subjects]. Med Lav 2000;91(3):217-25.

12. Charness ME, Ross MH, Shefner JM. Ulnar neuropathy and dystonic flexion of the fourth and fifth digits: clinical correlation in musicians. Muscle Nerve 1996;19(4):431-7.

13. ANACT, Inserm U88, INRS. Affections périarticulaires des membres supérieurs et organisation du travail: résultats de l'enquête épidémiologique nationale [Upper limb disorders and work organisation: results from a national epidemiological study]. Doc Méd Trav 1996;65:13-31.

14. Leclerc A, Franchi P, Cristofari MF, Delemotte B, Mereau P, Teyssier-Cotte $\mathrm{C}$, et al. Carpal tunnel syndrome and work organisation in repetitive work: a cross sectional study in France. Occup Environ Med 1998;55(3):180-7.

15. Leclerc A, Landre M-F, Chastang J-F, Niedhammer I, Roquelaure Y, the Study Group on Repetitive Work. Upper-limb disorders in repetitive work. Scand J Work Environ Health 2001;27(4):268-78.

16. Novak CB, Lee GW, Mackinnon SE, Lay L. Provocative testing for cubital tunnel syndrome. J Hand Surg [Am] 1994; 19(5):817-20.

17. Bazzini G. Aspetti anatomo-funzionali ed inquadramento diagnostico delle patologie da traumi ripetuti agli arti superiori [Anatomo-functional aspects and diagnosis algorithm of upper limb repeated trauma]. G Ital Med Lav Ergon 2001; 23(2):99-104.

18. Pujol M. Pathologie professionnelle d'hypersollicitation: atteinte périarticulaire du membre supérieur [Overuse syndrome: upper limb disorders]. Paris: Masson; 1993.

19. Terrono AL, Millender LH. Management of work-related upper-extremity nerve entrapments. Orthop Clin North Am 1996;27(4):783-93.

20. Toby EB, Hanesworth D. Ulnar nerve strains at the elbow. J Hand Surg [Am ] 1998;23(6):992-7.

21. Campbell WW. Ulnar neuropathy at the elbow. Muscle Nerve 2000;23(4):450-2.

22. Contreras MG, Warner MA, Charboneau WJ, Cahill DR. Anatomy of the ulnar nerve at the elbow: potential relationship of acute ulnar neuropathy to gender differences. Clin Anat 1998;11(6):372-8.

23. Tetro AM, Pichora DR. Cubital tunnel syndrome and the painful upper extremity. Hand Clin 1996;12(4):665-77.

24. Tsujino A, Itoh Y, Hayashi K, Uzawa M. Cubital tunnel reconstruction for ulnar neuropathy in osteoarthritic elbows. J Bone Joint Surg Br 1997;79(3):390-3.

25. Wright TW, Glowczewskie F Jr, Cowin D, Wheeler DL. Ulnar nerve excursion and strain at the elbow and wrist associated with upper extremity motion. J Hand Surg [Am ] 2001;26(4):655-62.

26. Green JR Jr, Rayan GM. The cubital tunnel: anatomic, histologic, and biomechanical study. J Shoulder Elbow Surg 1999; 8(5):466-70.

Received for publication: 6 June 2003 